immediately, are agreed. 'The modification of the water regimen of Canada's Arctic Drainage Basins will not be possible without certain changes in the very nature of the lands and waters of the North. However, decisions to modify the country should be taken in full knowledge of relevant facts and consequences, rather than by default. The state of knowledge in 1970 should make it possible to plan future water resource development in northern Canada more realistically, with more awareness of the full downstream impact of a modified regimen, than was possible when the Bennett Dam project was conceived and executed. No time should be lost in drafting and adopting large-scale land and water use plans for the provincial as well as the territorial parts of the Canadian Northlands. The North is vast, and all competing uses of land should be easy to accommodate. Unless land use is planned, however, we shall destroy a lot more of the natural values of this land than need be.'

The Brief to Government was mainly the work of the Water Resources Research Centre at the University of Alberta, and a major part in it was played by Dr. W.E. Stevens of the Canadian Wildlife Service.

\title{
The Tsavo Elephants
}

R. M. Laws

In the December 1970 Oryx we published an article by Dr Laws on his elephant research in the Tsavo National Park. This was written in 1968, and in this additional note he summarises the findings of later research, both by him and by other research workers, which support its conclusions, and also comments on the article by Dr P. E. Glover, Botanist Warden of the Tsavo Research Project, published in the September 1970 Oryx.

The article on the Tsavo Research Project was written in 1968; since then a number of other papers have been published which support the conclusions.

Laws (1969a) summarised the results of his studies on elephant reproduction, including the regulatory changes in a number of populations. Laws (1970a) presented a number of case histories of elephant populations and habitat change. He discussed the nature of the behavioural changes associated with contraction of range and habitat damage, and concluded that only in the case of the Serengeti is there reason to suppose that fire is of primary importance. Laws (1970b) summarized current knowledge of elephant biology.

Laws, Parker and Johnstone (1970) described the results of detailed studies in the Murchison Falls National Park and surrounding areas, which are to be published in full as a book-length monograph. They write, 'The analysis of the elephant populations indicates that they are at densities in excess of the carrying capacities of the habitats and the continuing changes in these habitats are described. In the grassland and wooded grassland areas the destruction of woodland has progressed radially, a zone of damage about $15.20 \mathrm{~km}$ wide having moved 
outwards through the range. This is consistert with destruction mainly by elephants rather than by fire'. Proposals for rational cropping of over 4,000 elephants, the construction of elephant proof barriers (to protect the forests) and the control of fire, have been made, and are being considered by the Uganda National Parks trustees.

Spence and Angus (in press) describe the initial results of experimental studies in Murchison Falls Park of the influence of fire and elephant (in exclosure plots). They conclude that 'shrub regeneration and herb improvement in Sporobolus-Setaria grassland will only follow reduction of grazing ... Fire protection in these grasslands without respite from grazing is probably of little value ... In CombretumTerminalia woodland, absence of both grazing and burning produces the most spectacular changes'.

Confirmation of the presence of a number of unit populations in the Tsavo ecological unit rather than a homogeneous population, was provided by Watson, Parker and Allan (1969). They showed that there were three distinguishable groups in the Mkomasi region totalling about 9,000 elephants and remark, 'This would appear to support the view of Laws (1968) that about 40,000 elephants inhabit the Tsavo region, since on this basis between 7,000 and 8,000 elephants have been predicted for the Mkomasi populations'.

\section{The Other View}

All the papers referred to above present factual evidence on which the conclusions are based. It is an indication of the complacency in Tsavo that Glover (1970) does not find it necessary to present any evidence to justify inaction. His article indicates that in the past two years no further studies on elephant population dynamics have been made. These are proposed for the future. But in any case a purely observational approach will not yield the information required for management. Dr Glover's article invites some further comments, since it is misleading. In the absence of information on how reliable and comparable the counting techniques were and specification of the areas counted, it is not possible to evaluate or accept the results. In fact 15,678 elephants were counted in the Park in 1965 (Laws, 1970, table 1), not 20,300 and the total population is certainly very much higher than either of these figures. A difference of one elephant in 20,000 is in any case absurd; no counts can be so accurate, and it would be reasonable to attach a range of error of several thousand to this figure.

The 'upward trend in rainfall' is a larger than usual one in a series of cycles since the 1930's (see Laws, 1969a, fig. 4), and has resulted in a temporary improvement of the habitats. The destruction of trees and bush may have temporarily improved the carrying capacity of the area for plains game, but it is arguable whether this will be maintained, and certainly disputable in respect of bush-requiring species. Goddard (1970a) remarks that habitat destruction continued in early 1969 when the elephant, which previously concentrated on Commiphora, Acacia and Sterculia, began to destroy Delonix elata and Platycelyphium voense, trees which they formerly left almost untouched. He suggests that this may well be the preliminary phase of another crisis (predicted by Laws, 1969b). 
Dr Glover, discussing Goddard's work, remarks that 'it certainly appears that the thinos are not adversely affected by the large numbers of elephants, as is also indicated by the variety of plant species and the abundance of shrubby and herbaceous vegetation, which has grown up since the 1960-61 drought'. Since his name has been invoked to support the non-policy advocated by Dr Glover it is interesting to see that Goddard himself concludes that 'this marked increase in shrub cover has resulted partly from the relatively heavy and atypical rainfall during the last few years' (Goddard, 1970a). He concluded that competition between elephants and rhinoceros 'will probably reach crisis proportions in drought or very dry periods when more browse is consumed $\therefore$ ' He recommends that 'as a safety precaution, management of the elephant populations, involving reduction cropping, should be initiated in Tsavo. The possible survival of one of the largest and most spectacular populations of elephant and black rhinoceros left in existence may be at stake'.

This is a serious and urgent problem, affecting not only elephant, but other species depending on bush. It can only be solved by concurrent management and research, and time is rapidly running out.

\section{References}

Glover, P.E. (1970) The Tsavo and the elephants. Oryx, $10,323$.

Goddard, J. (1970a) Age criteria and vital statistics of a black rhinoceros population. E. Afr. Wildl. J., 8,105.

Goddard, J. (1970b) Food preferences of black rhinoceros in the Tsavo National Park. E. Afr. Wildl J., 8, 145.

Laws, R. M. (1968) Interactions between elephant and hippopotamus populations and their environments. $E$. A fr. agric. for $J, 33,140$.

Laws, R. M. (1969a) Aspects of reproduction in the African elephant, Loxodonta africana, J. Reprod. Fert. Suppl. 6, 193.

Laws, R.M. (1969b). The Tsavo Research Project. J. Reprod. Fert. Suppl. 6, 495.

Laws, R. M. (1970a) Elephants as agents of habitat and landscape change in Africa. Oikos, $21,1$.

Laws, R. M. (1970b) Biology of African elephants. Science Progr. 58, 251.

Laws, R. M., Parker, I. S. C., \& Johnstone, R. C. B. (1970) Elephants and habitats in North Bunyoro, Uganda. E. Afr. Wildl. J., 8, 1963.

Spence, D.H.N., and Angus, A. (in press). African grassland management. The

Scientific Management of Animal and Plant Communities for Conservation, Ed. E.

Duffey, Blackwell, Oxford.

Watson, R. M., Parker, I. S. C. and Allan, T. (1969) A census of elephant and other large mammals in the Mkomasi region of northern Tanzania and southern Kenya. E. Afr. Wildl. $J ., 7,11$.

\section{Top Earner}

Tourism in Kenya, which is largely based on wildlife, is now the country's major foreign currency earner, exceeding coffee.

\section{Sable in Swaziland}

Thirteen sable antelope have been taken to the Mlilwane Game Sanctuary in Swaziland by the South African WWF and released there - the first to be seen in Swaziland for over a hundred years.

\section{WWF Grants}

Applications for grants to the British National Appeal of the WWF must reach BNA, 7-8 Plumtree Court, London EC4A 4DN, not later than August 19th for consideration this year. 